\title{
Bacterial energy taxis: a global strategy?
}

\author{
Tobias Schweinitzer $\cdot$ Christine Josenhans
}

Received: 23 March 2010/Revised: 31 March 2010/ Accepted: 6 April 2010/Published online: 22 April 2010

(C) The Author(s) 2010. This article is published with open access at Springerlink.com

\begin{abstract}
A functional energy metabolism is one of the most important requirements for survival of all kinds of organisms including bacteria. Therefore, many bacteria actively seek conditions of optimal metabolic activity, a behaviour which can be termed "energy taxis". Motility, combined with the sensory perception of the internal energetic conditions, is prerequisite for tactic responses to different energy levels and metabolic yields. Diverse mechanisms of energy sensing and tactic response have evolved among various bacteria. Many of the known energy taxis sensors group among the methyl-accepting chemotaxis protein (MCP)-like sensors. This review summarizes recent advances in the field of energy taxis and explores the current concept that energy taxis is an important part of the bacterial behavioural repertoire in order to navigate towards more favourable metabolic niches and to survive in a specific habitat.
\end{abstract}

Keywords Energy taxis - Chemotaxis - MCP sensors . Bacterial metabolism

\section{Introduction: What is energy taxis?}

In a rapidly changing environment, it is necessary for bacteria to recognize these changes and to respond to them, in order to optimize metabolic conditions or to avoid

Communicated by Erko Stackebrandt.

T. Schweinitzer $\cdot$ C. Josenhans $(\square)$

Institute for Medical Microbiology and Hospital Epidemiology,

Hannover Medical School, Carl-Neuberg-Strasse 1,

30625 Hannover, Germany

e-mail: josenhans.christine@mh-hannover.de contact with toxic compounds. Motile bacteria display very rapid directed motility changes when information is sensed. This behavioural trait is mediated by methyl-accepting chemotaxis proteins (MCPs) and is relayed directly to the motility apparatus by the chemotaxis signal transduction pathway (Bren and Eisenbach 2000). MCP sensor-transducers (Szurmant and Ordal 2004) sense one or several stimuli and transduce a signal via the core chemotaxis components, CheA, CheW and $\mathrm{CheY}$, to the flagellar apparatus. This results in a switch of flagellar rotation. By repeatedly inverting the direction of flagellar rotation (principle of the "biased random walk"), the net direction of bacterial movement is changed, enabling the bacteria to gradually approach to or to depart from a certain stimulus (Bren and Eisenbach 2000; Wadhams and Armitage 2004; Miller et al. 2009). This navigation ability of bacteria and its basal mechanisms are common and widely understood (Bren and Eisenbach 2000; Wadhams and Armitage 2004; Miller et al. 2009; Adler 1969). Responding by altered motility patterns to changes in chemical composition of their environment ("chemotaxis") or internal energetic conditions (in this review termed "energy taxis"), motile bacteria can navigate to more favourable spatial niches, where their metabolic activity increases. Energy sensing using closely related sensing domains but coupled to distinct transducing domains can also feed into additional, different, signal transduction pathways. These may alternatively lead to changed motility and taxis, altered gene regulation or differential second messenger production (Taylor 2007; Kirby 2009). According to an earlier definition by Adler et al. (Adler 1969), chemotaxis was defined as a motility response to compounds that need not be transported or utilized by metabolism and can be sensed even in very low concentrations. Recently, chemotaxis has been perceived in a closer context with energy taxis, which 
mediates a tactic response to alterations in internal bacterial energy generation and therefore requires metabolic activity. As many compounds that are directly sensed by MCP-like sensors also influence metabolism, it is not useful to strictly separate between these two definitions. For reasons of scope, we will exclusively focus on the topic of energy taxis, as defined above, predominantly in the context of MCP-like sensors. Recent advances have broadened our knowledge in this specific field. Compounds affecting energy taxis can be either metabolizable substrates, e.g. carbon or nitrogen sources such as sugars, amino acids and organic acids, serve as an electron acceptor, e.g. oxygen, nitrate, fumarate, DMSO, or otherwise affect the bacterial metabolism, e.g. non-metabolizable substrate analoga or metabolic inhibitors (Alexandre et al. 2004; Taylor et al. 1999; Baraquet et al. 2009). Sensing an altered metabolism, as it is the case in energy taxis, provides a very efficient means of monitoring the bacterial environment and integrating different stimuli which impact on energy levels, already at the level of the sensor. Metabolizable substrates in general have to be present in higher concentrations, because the compound itself is not sensed directly. In contrast, in the case of classical chemotaxis, different chemical stimuli (for instance sugars or amino acids) are first sensed separately by MCP sensors and the signal integration takes place predominantly downstream, at the CheA/CheW and CheY complex (Khan et al. 1995). Energy taxis can be determined and quantitated by various methods, similar to those which are applied to chemotaxis (Table 1). We did not list again methods for phototaxis analysis, since these have been comprehensively summarized recently by (Hoff et al. 2009).

\section{Ubiquitous occurrence and diverse mechanisms of bacterial energy taxis}

Energy generation is an essential process; therefore, it is not surprising that energy sensing connected to targeted motility (taxis) has been reported in a multitude of different representatives of bacteria and archaea (e.g. Escherichia coli (Taylor 2007; Greer-Phillips et al. 2003; Edwards et al. 2006), Bacillus subtilis (Hou et al. 2000), Helicobacter pylori (Croxen et al. 2006; Schweinitzer et al. 2008), Pseudomonas aeruginosa (Hong et al. 2004b) Vibrio cholera (Boin and Hase 2007), Rhodobacter sphaeroides (Gauden and Armitage 1995), Desulfovibrio vulgaris (Fu et al. 1994), Shewanella oneidensis (Baraquet et al. 2009), environmental perchlorate-reducing bacteria (Sun et al. 2009) and Halobacterium salinarium (Zhang et al. 1996; Hou et al. 2000)). Corresponding to that large variety of bacteria, their habitats and their different metabolic requirements, diverse mechanisms of energy taxis have evolved. Four different major types of energy taxis or energy-related taxis mediated by MCP-like sensors are outlined in the following sections and in Fig. 1. Various dedicated proteins mediating energy taxis in bacteria are summarized in Table 2.

\section{MCP sensors for phototropic energy taxis}

Probably one of the earliest discoveries related to bacterial energy taxis was the directed movement of bacteria towards light (termed "phototaxis"; (Spudich et al. 1986; Alam et al. 1989; Yao and Spudich 1992); see also reviews by (Taylor and Zhulin 1999; Armitage and Hellingwerf 2003; Hoff et al. 2009). Although phototaxis is widely distributed and was described long ago, its diverse array of input sensors has only recently been understood better, mostly due to intensive whole genome sequencing efforts. Since light is the most important source of energy generation for various environmental bacteria (e.g. cyanobacteria, phototrophic archaea, phototrophic bacteria) which possess a light harvesting complex, phototaxis can be regarded as one important mode of energy-related taxis. Photosensory proteins are able to sense light/photons, frequently of very specific wavelengths. Different types of photosensory domains have been identified, among others the LOV (light, oxygen and voltage) and PHY (phytochrome-like) photosensors (Losi and Gartner 2008). Whereas LOV domains form a subset of the PAS domain superfamily, PHY family proteins frequently contain a GAF domain (cGMP phosphodiesterase/adenylate cyclase/ FhlA). Dedicated photoreceptor proteins can act as bipartite MCP photosensors, when their input domain is noncovalently associated and functionally coupled to MCP domain transducers, as first described in Halobacterium halobium (now H. salinarium) (HtrI/SR-I; (Yao and Spudich 1992); Table 2) and H. salinarium (Zhang et al. 1996). Only in few cases so far, phytochrome sensors directly fused to an MCP-like output domain have been implicated in phototaxis. The Synechocystis PCC6803 TaxD1 (alternative name PixJ1) is such an example carrying an MCP domain in its C-terminus and a PHY/GAF domain in its N-terminus (Losi and Gartner 2008). TaxD1 mediates phototaxis by pili-dependent motility in Synechocystis sp. ( $\mathrm{Ng}$ et al. 2003; Table 2). In the PHY family, up to 16 proteins with MCP domains were identified to date (Losi and Gartner 2008), indicating a widespread direct role of photoreceptors in the control of bacterial motility and tactic responses. In addition to direct light sensing by some MCP-like taxis sensors, light harvest translated into electron transfer in the electron transport chain can be sensed indirectly as one form of redox taxis, as has been described in R. sphaeroides (Gauden and Armitage 1995). It is also interesting to note that some photosensory 
Table 1 Methods used to characterize bacterial energy taxis

\begin{tabular}{|c|c|c|c|c|}
\hline Assay & Description & Advantage & Disadvantage & Examples and references \\
\hline \multicolumn{5}{|c|}{ Temporal assays ${ }^{\mathrm{a}}$} \\
\hline $\begin{array}{l}\text { Tethered } \\
\text { cell assay }\end{array}$ & $\begin{array}{l}\text { Flagella are attached to a } \\
\text { surface by antibodies; rotation } \\
\text { direction of bacterial single } \\
\text { cells is microscopically } \\
\text { observed }\end{array}$ & $\begin{array}{l}\text { Application of attractants } \\
\text { and repellents in a flow cell } \\
\text { possible }\end{array}$ & $\begin{array}{l}\text { No substance gradient present } \\
\text { which allows true tactic } \\
\text { movement, requires shearing } \\
\text { and attaching of flagella to } \\
\text { surface }\end{array}$ & $\begin{array}{l}\text { Not used for energy taxis so far; } \\
\text { commonly used for } \\
\text { chemotaxis assays in } E \text {. coli }\end{array}$ \\
\hline $\begin{array}{l}\text { Bacterial } \\
\text { tracking }\end{array}$ & $\begin{array}{l}\text { Medium can include metabolic } \\
\text { substrates or inhibitors; stops, } \\
\text { curvilinear velocity, time } \\
\text { kinetics can be determined }\end{array}$ & $\begin{array}{l}\text { No bacterial proliferation } \\
\text { necessary }\end{array}$ & $\begin{array}{l}\text { No gradient present; tracking } \\
\text { microscopy equipment } \\
\text { required }\end{array}$ & $\begin{array}{l}\text { E. coli Bespalov et al. (1996); } \\
\text { A. brasilense Zhulin et al. } \\
\text { (1996); H. pylori Schweinitzer } \\
\text { et al. (2008) }\end{array}$ \\
\hline \multicolumn{5}{|c|}{ Spatial assays ${ }^{\mathrm{b}}$} \\
\hline $\begin{array}{l}\text { Motility } \\
\text { plates }\end{array}$ & $\begin{array}{l}\text { Soft agar plates with a defined } \\
\text { bacterial inoculum; radial } \\
\text { motility is determined as a } \\
\text { measure of behaviour }\end{array}$ & $\begin{array}{l}\text { Isolation of single clones is } \\
\text { possible due to high } \\
\text { accessibility }\end{array}$ & $\begin{array}{l}\text { Bacterial proliferation and } \\
\text { motility are prerequisite; not } \\
\text { suitable for bacteria which } \\
\text { need non-defined complex } \\
\text { media for proliferation }\end{array}$ & $\begin{array}{l}\text { E. coli; } \text { A. brasilense Alexandre } \\
\text { et al. (2000); V. cholera Boin } \\
\text { and Hase (2007); C. jejuni } \\
\text { Hendrixson et al. (2001); } \\
\text { P. putida Nichols and } \\
\text { Harwood (2000) }\end{array}$ \\
\hline $\begin{array}{l}\text { Capillary } \\
\text { energy } \\
\text { taxis } \\
\text { assay }\end{array}$ & $\begin{array}{l}\text { Glass capillary filled with } \\
\text { medium and test substance } \\
\text { (can be a metabolic substrate) } \\
\text { is inserted in bacterial } \\
\text { suspension; number of } \\
\text { bacteria entering the capillary } \\
\text { is determined }\end{array}$ & $\begin{array}{l}\text { Enables screening of a high } \\
\text { number of substances; no } \\
\text { bacterial proliferation } \\
\text { needed; measurements can } \\
\text { be taken within minutes }\end{array}$ & $\begin{array}{l}\text { Bacteria need to be highly } \\
\text { motile under anaerobic } \\
\text { conditions due to the reduced } \\
\text { gas diffusion within the } \\
\text { capillary; otherwise, trapping } \\
\text { effects can occur }\end{array}$ & B. subtilis Ordal et al. (1979) \\
\hline $\begin{array}{l}\text { Capillary } \\
\text { aerotaxis } \\
\text { assay }\end{array}$ & $\begin{array}{l}\text { Glass capillary is half-filled } \\
\text { with a bacterial suspension, } \\
\text { ventilated with defined gas } \\
\text { atmosphere closed at both } \\
\text { ends; distance of the bacterial } \\
\text { accumulation to the meniscus } \\
\text { is measured }\end{array}$ & $\begin{array}{l}\text { Enables screening of a high } \\
\text { number of mutants or } \\
\text { conditions; no proliferation } \\
\text { needed; rapid observation } \\
\text { and measurements }\end{array}$ & $\begin{array}{l}\text { Bacteria need to be highly } \\
\text { motile under anaerobic } \\
\text { conditions due to the reduced } \\
\text { gas diffusion within the liquid } \\
\text { inside the capillary }\end{array}$ & $\begin{array}{l}\text { E. coli Rebbapragada et al. } \\
\text { (1997); A. brasilense (Zhulin } \\
\text { et al. (1996); Greer-Phillips } \\
\text { et al. (2004); V. cholera Boin } \\
\text { and Hase (2007); P. putida } \\
\text { Nichols and Harwood (2000) }\end{array}$ \\
\hline $\begin{array}{l}\text { Chamber } \\
\text { assay }\end{array}$ & $\begin{array}{l}\text { Custom made or commercial } \\
\text { system; number of bacteria } \\
\text { that migrate from one } \\
\text { reservoir to another along a } \\
\text { preformed chemical gradient } \\
\text { can be counted }\end{array}$ & $\begin{array}{l}\text { Enables screening of a high } \\
\text { number of mutants or } \\
\text { conditions; exact mounting } \\
\text { of a defined substance } \\
\text { gradient is possible }\end{array}$ & System has to be well ventilated & $\begin{array}{l}\text { H. pylori Schweinitzer et al. } \\
\text { (2008); S. oneidensis Baraquet } \\
\text { et al. (2009) }\end{array}$ \\
\hline
\end{tabular}

\footnotetext{
${ }^{\text {a }}$ Free-swimming bacteria are directly observed in appropriate media under specific gas atmosphere; stimulus (chemical, gas) is added and ensuing changes in the swimming pattern are measured; no gradient of stimulus

${ }^{\mathrm{b}}$ Can be performed in liquid and in solid media; changes in orientation of bacterial population or single cell are observed; stimulus gradient is preformed
}

proteins of cyanobacteria, such as Synechocystis sp. PCC6803 PixD (which carries, however, no MCP domain itself), can directly interact with metabolic enzymes (glucokinase and glycogen phosphorylase), connecting light activation to glucose catabolism and intermediary metabolism (Hoff et al. 2009).

\section{PAS-domain MCP energy taxis sensors}

Sensing a stimulus originating in the electron transport chain is one suitable mechanism of integrating different metabolic parameters. The best characterized energy taxis sensor closely linked to the bacterial electron transport chain is $E$. coli Aer. It is a representative of a PAS domain-containing receptor-MCP family that do not have a periplasmic domain but face the cytoplasm and are linked to the membrane by an anchor of hydrophobic amino acids (Taylor 2007; Amin et al. 2006). Proteins containing a PAS structural fold were originally named for three different eukaryotic proteins, Per-ARNT-Sim (period, hydrocarbon receptor nuclear translocator, singleminded). The PAS domain superfamily in life forms is very diverse, comprising at least 14.900 sensory molecules (current SMART and MIST databases (Letunic et al. 2009; Ulrich and Zhulin 2010)), and includes transducer molecules that can sense light, oxygen or 

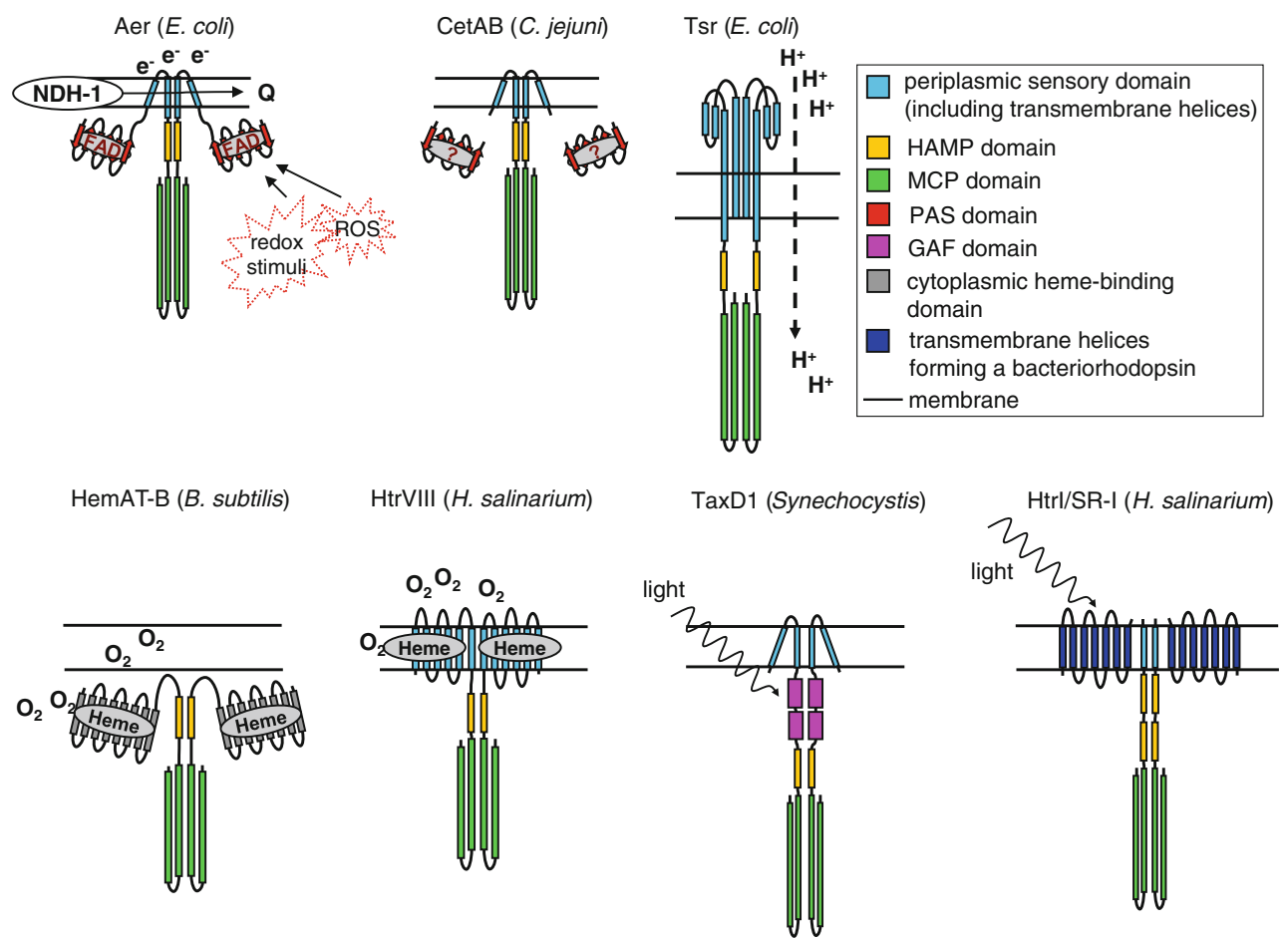

Fig. 1 Schematic overview of representative examples for different proposed bacterial energy taxis sensors and energy-related taxis sensors. In general, stimuli are sensed by MCP receptor dimers that can be associated in receptor clusters. Signals from MCPs are transduced via the chemotaxis core components CheA and CheY to the motility apparatus (this can be flagella or non-flagellar motility

redox potential as input signals (Taylor 2007). Aer binds FAD as a cofactor and guides the bacteria in a gradient of rapidly oxidizable substrates (Greer-Phillips et al. 2003). Aer-dependent tactic responses were experimentally linked to redox changes of the cell (Edwards et al. 2006). Since the PAS domain and FAD binding are essential for Aer function, it seems to be the most likely sensory/input domain (Taylor 2007; Rebbapragada et al. 1997; Taylor et al. 2001; Bibikov et al. 2000). In the current model for Aer function, PAS-FAD reacts to changes in the cellular redox state by interacting either with a cytosolic electron donor or directly with the electron transport chain (Edwards et al. 2006). A role of NADH dehydrogenase I in Aer-based energy sensing, possibly by protein-protein interaction, was suspected (Edwards et al. 2006). Aer contains a HAMP (histidine kinases, adenylyl cyclases, methyl-accepting chemotaxis proteins, phosphatases) domain, which cooperates with the PAS domain and propagates the signal towards the MCP domain (BuronBarral et al. 2006; Taylor 2007) An energy taxis signal is transduced, probably via a direct interaction of the PAS with the HAMP domain, resulting in a conformational change which affects the signalling ability of the MCP domain of the protein (Taylor 2007; Watts et al. 2008).

systems such as pili or gliding motility). Proposed stimuli or sensing mechanisms are depicted together with the model of each sensor type. $N D H-1$ NADH dehydrogenase I, $Q$ quinone pool, $R O S$ reactive oxygen species. For other abbreviations and specific sensor names, see text

Aer interacts with other MCPs in chemoreceptor arrays (Hazelbauer et al. 2008), but it is also able to exert its energy taxis function by itself (Taylor 2007).

Besides E. coli Aer, various related MCP-like bacterial energy sensors were described which contain PAS domains: V. cholerae Aer-1, Aer-2 and Aer-3 (Boin and Hase 2007), P. aeruginosa Aer (formerly: TlpC) and Aer-2 (formerly: TlpG) (Hong et al. 2004b), Ralstonia solanacearum Aer1 and Aer2 (Yao and Allen 2007) and Azospirillum brasilense AerC (Xie et al. 2010). Another variation of this theme is bipartite Aer-like redox taxis sensors such as CetA/CetB, which were first identified in Campylobacter jejuni (Hendrixson et al. 2001). This type of energy taxis sensors, as the bipartite photosensors, consists of two physically separate proteins: one PASdomain sensory protein (CetB) and an associated transducer protein (CetA). The sensory protein (CetB) supposedly detects the energy/redox status of the cell, whereas the transducer protein, which contains the HAMP and the MCP domains, propagates the signal towards the motility apparatus. Up to now, bipartite energy sensors were identified in 55 species in a variety of bacterial taxa (Elliott et al. 2009). One can speculate that bipartite sensors enable the bacterium to combine 
Table 2 Overview of MCP-like energy-related taxis sensors described or characterized so far (source: SMART database, MIST2 database)

\begin{tabular}{lllll}
\hline Species & $\#$ Name & Domain architecture & Proposed function/mechanisms & Reference \\
\hline E. coli & 2 Aer & $\begin{array}{c}\text { Interaction with electron transport } \\
\text { system; involvement of NADH } \\
\text { dehydrogenase }\end{array}$ & $\begin{array}{c}\text { Rebbapragada et al. (1997) } \\
\text { and Edwards et al. (2006) }\end{array}$ \\
& Tsr & PMF measurement
\end{tabular}
A. brasilense $\quad>2$ Tlp 1

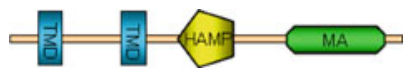
Unknown; possible Tsr like
Greer-Phillips et al. (2004)

AerC

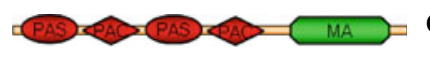

Carrying a PAS domain and FAD as cofactor, interaction with cellular redox state?

R. solanacearum

2 Aer1

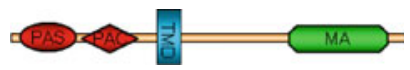

Unknown; probably similar to E. coli Aer

Yao and Allen (2007)

Aer2

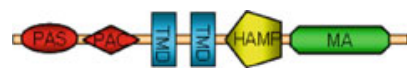

V. cholerae

$>3$ Aer-1

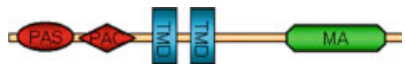

Unknown; probably similar to E. coli Aer Boin and Hase (2007)

Aer-2

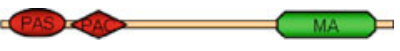

Aer-3

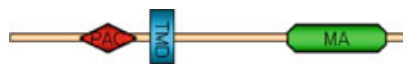

P. aeruginosa

2 Aer

(TlpC)

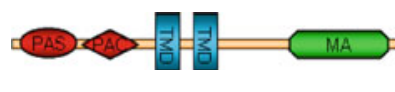

Unknown; probably similar to E. coli Aer Hong et al. (2004b)

Aer-2

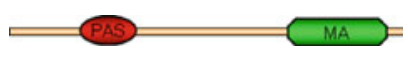

(TlpG)

H. pylori

2 TlpB

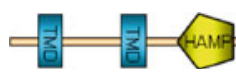

Unknown; maybe Tsr sensing since $\mathrm{pH}$ sensing was shown

Croxen et al. (2006);

Unknown; experimental evidence for an

TlpD

MA interaction with electron transport system 
Table 2 continued

\begin{tabular}{|c|c|c|c|c|c|}
\hline Species & \# & Name & Domain architecture & Proposed function/mechanisms & Reference \\
\hline H. hepaticus & ND & НH0891 & & $\begin{array}{l}\text { Unknown; identified by sequence } \\
\text { homology to TlpD of } H \text {. pylori }\end{array}$ & Suerbaum et al. (2003) \\
\hline \multirow[t]{2}{*}{ C. jejuni } & 3 & Aer1 & $\mathrm{Cr}$ & Unknown; probably similar to E. coli Aer & $\begin{array}{l}\text { Hendrixson et al. (2001), } \\
\text { Elliott and DiRita (2008), } \\
\text { Elliott et al. (2009) }\end{array}$ \\
\hline & & $\begin{array}{l}\text { CetAB } \\
\text { (Tlp9/ } \\
\text { Aer2) }\end{array}$ & & $\begin{array}{l}\text { Bipartite sensor; mechanism probably } \\
\text { similar to } E \text {. coli Aer }\end{array}$ & \\
\hline
\end{tabular}

B. subtilis $>1$ Hem

AT

MA = Direct oxygen sensing

Hou et al. (2000)

H. salinarium >3 Hem-

(H. halobium)

AT

Direct oxygen sensing

Hou et al. (2000)

HtrVIII

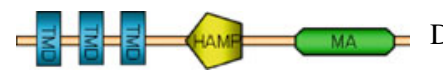

Direct oxygen sensing

Brooun et al. (1998)

HtrI/SR-

I

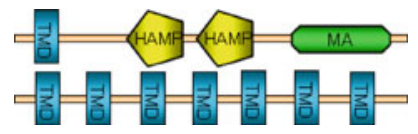

Bipartite photoreceptor consisting of a sensory rhodopsin I (SR-I) and methylaccepting protein (HtrI)

D. vulgaris 1 DcrA

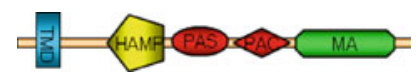

Direct oxygen sensing
Synechocystis sp. 1 TaxD1 strain PCC6803

S. oneidensis

$5 \mathrm{SO} 2240$

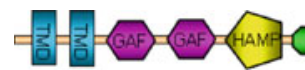

MA
Light sensing and taxis; probably via GAF domain

Unknown, authors propose an involvement of a cache domain
Fu et al. (1994)

Yao and Spudich (1992)

Losi and Gartner (2008)

Baraquet et al. (2009)

\# Proposed number of energy taxis sensors present in bacterial species (ND not detected)

the sensing properties of a sensor with different kinds of separate transducing domains or functions, maybe even with elements mediating gene regulation. By this means, organisms would be enabled to respond simultaneously in more than one way to changes in metabolic activity. 
PMF sensing by MCP taxis sensors

Another class of bacterial energy taxis sensors, exemplified by Tsr, originally identified in $E$. coli, is structurally and functionally distinct from PAS domain sensors (Edwards et al. 2006; Rebbapragada et al. 1997). In contrast to Aer, Tsr has a classical MCP structure (Szurmant and Ordal 2004; Taylor 2007), with two transmembrane domains and a variable N-terminal, periplasmic domain (loop), which serves as the main sensory input domain for chemical stimuli (e.g. serine). The N-terminal sensor portion is followed by an alpha-helical HAMP and the highly conserved C-terminal alpha-helical MCP domain (Szurmant and Ordal 2004; Taylor 2007). E. coli Tsr responds to serine, oxygen (Rebbapragada et al. 1997), carbon sources (GreerPhillips et al. 2003), pH (Umemura et al. 2002) and temperature (Lee et al. 1988). Responses by Tsr to carbon sources directly correlate with the adequacy of the carbon source for growth (Greer-Phillips et al. 2003). Tsr also mediates taxis to an electron acceptor. Therefore, Tsr was hypothesized to sense proton motive force (PMF). PMF can be regarded as the final outcome of energy generation and therefore as a suitable stimulus for sensing metabolic activity. Edwards et al. (2006) recently proved experimentally that a link exists between PMF and Tsr-mediated tactic behaviour. Probably, PMF sensing is achieved by charged amino acids in the Tsr HAMP domain, similar to pH sensing by Tsr (Umemura et al. 2002). However, the crucial amino acids have not yet been identified (Edwards et al. 2006). Although there are no other Tsr-like sensors for which a direct connection to PMF is known, at least among the Enterobacteriaceae, numerous MCPs with significant sequence homology to Tsr exist.

\section{Hem-AT-like MCP aerotaxis sensors}

A fourth group of proposed energy-related sensors is HemAT-like MCP taxis sensors, which directly sense haemebound oxygen. A strict definition of energy taxis would not permit to group Hem-AT-like sensors amongst energy sensors, since the ligand (oxygen) is bound directly. This affinity is presumably independent of metabolic activity. Since oxygen is one important chemical equivalent of aerobic metabolism, these MCPs can still be regarded as energy-related sensors in a broader sense and we will discuss them jointly. Originally identified in $D$. vulgaris (DcrA; (Fu et al. 1994)), similar proteins are also present in other eubacterial and archaeal species (e.g. B. subtilis, H. salinarium; (Zhang et al. 1996; Hou et al. 2000). DcrA of D. vulgaris possesses a c-type haeme-binding site in its $\mathrm{N}$-terminal domain. Fu and coworkers demonstrated haeme binding in DcrA and the dependence of the methylation state of DcrA on the redox state of the haeme iron. Since the obligate anaerobe $D$. vulgaris displays aerotaxis towards very low oxygen concentrations $(\sim 0.04 \%)$ (Johnson et al. 1997), the existence of an oxygen sensor seems to be plausible. Similar sensors in Bacillus (HemAT-B) and Halobacterium (Hem-AT-H) were reported to possess a b-type haeme (Hou et al. 2000), which binds to the globin-like sensing domain of the receptor. An aerotactic response (taxis to or away from oxygen) mediated by these haeme-containing MCPs was shown for both sensors. Whereas Hem-AT-H in $H$. salinarium seemed to mediate an aerophobic response, Hem-AT-B in B. subtilis mediated an aerophilic response. In spectral analyses, a direct interaction of these sensors with diatomic oxygen and a subsequent conformational change were demonstrated (El Mashtoly et al. 2008). These Hem-AT sensors lead bacteria differentially to their preferred oxygen concentration (Hou et al. 2000).

\section{Ecophysiological role of energy taxis}

Chemotaxis genes or components have been identified in a large variety of bacterial species (Alexandre et al. 2004; Szurmant and Ordal 2004). Surprisingly, specific energyrelated tactic behaviour has only been described in relatively few bacterial species (for some examples see: (Hou et al. 2000; Nichols and Harwood 2000; Gauden and Armitage 1995; Lee et al. 2002)). The molecular background and roles of such a fundamental principle as energy sensing and taxis are understood only for few species to date (previously highlighted in (Alexandre et al. 2004)). To understand the impact of energy taxis on the life cycle of a bacterium, we also need to understand habitat, gene regulation and overall metabolic capacities, making the story much more complex. In the following paragraphs, we will review the current knowledge on energy taxis, focussing on some examples from the alpha-, beta-, gamma- and epsilonproteobacteria and one Gram-positive bacterium.

Plant and soil-associated bacteria

Among the first bacterial species shown to display energy taxis as a dominant behaviour was the alphaproteobacterium A. brasilense (Alexandre et al. 2000). A. brasilense is a free-living diazotroph, which is associated with the roots of many agriculturally important plants (Greer-Phillips et al. 2004). It has a predominantly aerobic lifestyle with preference for a microaerobic atmosphere $(<1 \%$ oxygen) (Zhulin et al. 1996) and fructose or organic acids as growth substrates (Alexandre et al. 2000). It can also use nitrate as an alternative electron acceptor. Nitrogen fixation, which is central to this bacteria-plant interaction, occurs only under low oxygen concentrations (Zhulin et al. 1996). The 
bacteria show positive taxis towards oxidizable substrates, alternative electron acceptors (Alexandre et al. 2000) and to an oxygen concentration optimal for microaerobic energy generation and nitrogen fixation (Zhulin et al. 1996). Since the tactic response to a carbon source correlated with the suitability of the chemical as a growth substrate, and chemicals which do not support growth were not attractants, the authors concluded that energy taxis is a dominant behaviour in A. brasilense. Moreover, metabolic inhibitors totally abolished tactic behaviour. The MCP sensor Tlp1 was shown to mediate energy taxis (GreerPhillips et al. 2004). Tlp1 contains no PAS domain, and the response to a chemical correlated with its suitability as growth substrate (Alexandre et al. 2000). Thus, the sensory capacities of Tlp1 might be similar to E. coli Tsr (GreerPhillips et al. 2003). Finally, tlpl mutants were drastically impaired in their ability to navigate to the preferred niche in the rhizosphere and in root colonization. Since taxis to metabolizable molecules was still occurring in a tlpl mutant, other energy sensors were suspected in A. brasilense. Recently, this hypothesis was confirmed with the characterization of a second dedicated MCP-like energy taxis sensor, AerC, containing two PAS domains (Xie et al. 2010). AerC specifically mediated taxis towards a microaerobic environment which facilitates nitrogen fixation. Since taxis to root exudates is one of the first steps of plant colonization, the authors suggest that energy taxis is one dominant way to lead Azosprillum to a broad and supposedly variable range of chemicals that support metabolism (Greer-Phillips et al. 2004; Xie et al. 2010) and towards a niche of low oxygen concentration, where nitrogen fixation can be achieved (Xie et al. 2010). Overall, a major role of energy taxis in the habitat of A. brasilense is likely.

Ralstonia solanacearum is a plant pathogen belonging to the betaproteobacteria. It causes wilt disease in diverse plant species. Although the physiology of $R$. solanacearum has not yet been analyzed comprehensively, the metabolism seems to be quite versatile. Strains of the species use a wide range of growth substrates that enable long-term survival in habitats such as surface water and different soils (Genin and Boucher 2004). Since chemotaxis mutants (cheA, cheW) display decreased virulence and poor host colonization, taxis seems to be necessary for navigating towards a plant host and infecting it efficiently (Yao and Allen 2006). The genome of $R$. solanacearum contains 20 MCPs of which two, Aer1 and Aer2, are similar to E. coli Aer. These proteins restored the wild-type phenotype to an $E$. coli aer mutant, indicating functional equivalence to Aer. Yao and coworkers showed in vitro that $R$. solancearum aer mutants (aer1, aer2, aerl/aer2) lost their ability to move upwards in an oxygen gradient. These bacteria were also delayed in causing disease and furthermore impaired in their ability to locate and aggregate on plant roots (Yao and Allen 2007). Therefore, energy taxis appears to play a central role for $R$. solanacearum in finding and colonizing the preferred plant niche and is therefore supposed to be an important element of its habitat-specific survival strategy.

Phototaxis by bipartite MCP sensor/transducers or composite MCPs is also one related mode of energy-related taxis which is predicted to play a crucial role in the environmental soil or water habitat.

Escherichia coli and Pseudomonas ssp.: bacteria colonizing at least two divergent habitats

Several gammaproteobacterial species, including those of the Enterobacteriaceae, have been investigated in more detail in the context of energy sensing. One of the best characterized bacteria regarding its metabolic properties, and also its tactic behaviour and the underlying molecular principles is E. coli. E. coli carries five MCP molecules of which two function as energy sensors, Tsr and Aer (Edwards et al. 2006; Rebbapragada et al. 1997). Both mediate movement towards a carbon source, an appropriate oxygen concentration (Greer-Phillips et al. 2003) and alternative electron acceptors under anaerobic conditions (Taylor et al. 1979). The E. coli electron transport system comprises two different NADH dehydrogenases, two terminal oxidases and several components for anaerobic respiration, enabling the alternative or simultaneous use of various electron donors and acceptors present in the environment (Edwards et al. 2006). Although aerotactic behaviour was not dominant under conditions tested in vitro, we hypothesize that energy taxis plays an important role in the ecology of E. coli, because in its divergent natural habitats such as the mammalian and avian intestine or sewage, oxygen is one of the growth-limiting parameters. E. coli, which has a limited physiological range for anaerobic energy generation, is supposed to preferentially navigate towards an aerobic niche, since energy yield is much higher under aerobic conditions (Tran and Unden 1998). Although Aer and Tsr are well investigated, only little is known about their role in the natural habitat of E. coli. A defect in colonizing the mouse large intestine was reported recently for E. coli mutants lacking Aer (Horne et al. 2009). In this setting, the defect was rather correlated with the proposed regulatory role of Aer than with its direct role in energy taxis, but both are suspected to be closely connected by the active metabolic properties. Moreover, host-specific differences in tactic abilities were recently demonstrated by comparing $E$. coli isolates from different mammalian hosts (carnivore, herbivore, omnivore; (Dzinic et al. 2008)), which may be linked to energy taxis. The energy yield and substrate availability in the 
intestine can be modulated by the uptake of specific nutrients and by a diverse array of commensal microbiota inhabiting this niche. This work underlines again the importance of taxis for colonizing a habitat and earmarks energy taxis as one possible mechanism to establish host specificity.

Pseudomonas aeruginosa is a ubiquitous bacterium which also plays an important role as an opportunistic pathogen in Cystic Fibrosis or burn wound patients. $P$. aeruginosa proliferates under anaerobic conditions using nitrate as an electron acceptor (Carlson and Ingraham 1983) or by fermentation of arginine in the absence of nitrate (Vander et al. 1984). Pathways of anaerobic energy generation are repressed under aerobic conditions, indicating a preference for aerobic energy generation.

One particular natural habitat of $P$. aeruginosa recently shown to be partially anaerobic is advanced biofilms in the airway lumen of patients with CF (Yoon et al. 2002). $P$. aeruginosa possesses four distinct chemotaxis systems (che1, che2, pil-chp, wsp), organized in five clusters. Whereas systems che1 and che 2 control tactic motility, system pil-chp controls type VI pilus formation and twitching motility. The wsp system is involved in biofilm formation. Altogether, at least 26 genes encoding MCPlike molecules are present. At least two of them, the PAS proteins Aer and Aer-2 (components of che1 and che2), resemble $E$. coli Aer. Both proteins function as redox or energy sensors (Hong et al. 2004b; Nichols and Harwood 2000). A mutant deficient in both genes (aer and aer-2) did not display any aerotactic response. Whereas aer-2 transcription is RpoS dependent and occurs in the stationary phase (condition prevailing in biofilms), aer is induced under oxygen-limited conditions via an FNR/ ANR-dependent promoter (Galimand et al. 1991; Hong et al. 2004a). Neither the role of energy taxis by $P$. aeruginosa in its diverse habitats and physiological states is well investigated nor whether and how it affects flagella-independent twitching motility. For several Pseudomonas species ( $P$. fluorescens, P. syringae and $P$. aeruginosa), chemotaxis was shown to be important for promoting plant growth, plant infection or animal infection (Kato et al. 2008). We speculate that energy taxis (so far characterized in $P$. aeruginosa as aerotaxis) is important for dynamic responses of $P$. aeruginosa to its diverse natural habitats.

\section{Helicobacter pylori and Campylobacter jejuni, highly host-adapted gastrointestinal bacteria}

The group of $\varepsilon$-proteobacteria comprises several persistently host-associated or pathogenic bacteria. For two representatives (H. pylori, $C$. jejuni), metabolism-dependent tactic behaviour has been shown to date (Hendrixson et al. 2001; Schweinitzer et al. 2008).
Helicobacter pylori is one of the most frequent pathogens of humans. H. pylori and related bacteria (Helicobacter sp.) persistently colonize the stomach and intestinal tracts of their mammalian hosts. Since $H$. pylori possesses only one terminal oxidase (Cbb3-type), it is restricted to a very limited range of atmospheric conditions. It has been described as a microaerophilic capnophilic bacterium with an optimal oxygen concentration of about $5 \%$ and an absolute requirement for carbon dioxide (St Maurice et al. 2007). Although components of anaerobic respiration (fumarate reductase, $\mathrm{S} / \mathrm{N}$-oxide reductase) are present (Schweinitzer et al. 2008), bacterial proliferation under anaerobic conditions in the laboratory was not achieved (Lancaster and Simon 2002). This indicates an absolute requirement of oxygen for its proliferative life cycle. H. pylori requires flagellar motility and taxis throughout its life-long host association (Eaton et al. 1996; Kavermann et al. 2003). A pH gradient exists between the highly acidic stomach lumen and the less acidic mucus layers covering the stomach epithelium. This gradient is important to instruct the localization, orientation and survival of the bacteria in situ. The bacteria accumulate in a well-defined layer of low acidity in the stomach mucus (Schreiber et al. 2004), indicating abilities of energy taxis. A proper localization within this narrow zone was shown to be essential, since the more acidic $\mathrm{pH}$ prevailing in the gastric lumen rapidly impaired motility (Schreiber et al. 2005). Two different $H$. pylori energy sensors have recently been characterized (sensing $\mathrm{pH}$ or changes in electron transport). Negative $\mathrm{pH}$ taxis away from low $\mathrm{pH}(\mathrm{pH}<3)$ was reported to be mediated by one transmembrane $\mathrm{MCP}, \mathrm{TlpB}$ (Croxen et al. 2006). TlpB mutants were attenuated in mouse colonization. Although it is not clear whether the $\mathrm{pH}$ gradient itself is sensed by $\mathrm{TlpB}$, these findings suggest a role of $\mathrm{pH}$ taxis in infection and persistence. The described $\mathrm{pH}$ taxis is proposed to be linked to energy taxis via $\mathrm{PMF}$, since very low external $\mathrm{pH}$ was shown to influence the PMF and energy level of $H$. pylori (Stingl et al. 2002). Mutants deficient in $t$ lpB induce less inflammation in gerbil and mouse infection models than in the wild type (McGee et al. 2005; Williams et al. 2007). The inability to precisely orient in the stomach mucus might result in a decreased potential to cause inflammation.

A second, dominant mechanism of energy taxis in H. pylori is provided by a soluble MCP sensor, TlpD, which mediates a reaction to changes in the electron transport chain (Schweinitzer et al. 2008). A mutant deficient in tlpD was severely impaired in metabolism-dependent taxis and lost its repellent response to increasing concentrations of a metabolic inhibitor. The existence of at least two energy sensors (of four MCP-like proteins) in this species stresses the importance of energy sensing in its habitat. Since energy taxis was the dominant behaviour under in vitro 
conditions and taxis is known to be a key prerequisite for successful colonization (Kavermann et al. 2003; McGee et al. 2005), it seems quite plausible that energy taxis plays a crucial role in situ for this bacterium with limited metabolic abilities. TlpD-like molecules are also present in closely related Helicobacter ssp. and in Campylobacter jejuni and $C$. coli, two human pathogens of the intestinal tract.

In C. jejuni, at least ten MCP-like proteins have been identified. In addition, two Aer-like proteins (Aer1, Aer2), containing a PAS domain but no MCP domain, have been reported (Marchant et al. 2002). One of these (Aer2) is part of a bipartite sensor (CetAB), consisting of a sensing domain (CetB is Aer2) and an MCP signalling domain (CetA) (Hendrixson et al. 2001; Elliott and DiRita 2008). Whereas CetAB mediated energy taxis and was essential for this behaviour, the role of Aer1 is unclear. C. jejuni preferentially moves towards metabolizable substrates, and impaired energy taxis affected cell interactions in vitro (Vegge et al. 2009). Tactic motility was already reported previously as an important mechanism in Campylobacter host colonization (Takata et al. 1992; Yao et al. 1997). Campylobacter, like H. pylori, prefers microaerobic habitats. Anaerobic electron acceptors such as fumarate, nitrate, nitrite, TMAO or DMSO supported growth under microaerobic conditions (Sellars et al. 2002) and were sufficient to enable anaerobic growth under certain laboratory conditions. Still, oxygen remains the most important respiratory electron acceptor for this bacterium (Weingarten et al. 2008). C. jejuni can colonize similar habitats as $E$. coli, in particular in the upper animal intestine, where oxygen is one limiting parameter. Oxygen-dependent respiration was shown to be essential for $C$. jejuni in vivo, since cco (high-affinity terminal oxidase) mutants can grow in vitro but are unable to infect chickens (Weingarten et al. 2008). Therefore, energy taxis/aerotaxis has to be an important prerequisite for host colonization and pathogenesis of $C$. jejuni, which could also be linked to host or niche specificity.

\section{Bacillus subtilis}

The Gram-positive Firmicutes B. subtilis also displays energy tactic behaviour. Like other aerotactic bacteria, $B$. subtilis migrates to environments where the oxygen concentration is optimal for its metabolism (Wong et al. 1995). Mutants lacking the Hem-AT sensor, which mediates an aerophilic response, still displayed aerotactic behaviour (Hou et al. 2000). Therefore, B. subtilis is likely to possess at least one additional oxygen or different energy sensor, mediating an aerophobic response away from high concentrations of oxygen. The existence of at least two sensors, mediating a divergent response to oxygen, underlines that an appropriate concentration of oxygen is highly important for respiration in B. subtilis. Anaerobic growth occurred in vitro, but aerobic energy generation is clearly preferred, and pathways of anaerobic energy generation are strictly regulated in B. subtilis (Cruz et al. 2000; Ye et al. 2000). Still, B. subtilis can grow in oxygen-limited environments such as soils, on plant roots or within the intestinal tract of animals (Earl et al. 2008; Nakano and Zuber 1998), where energy taxis might be an economic means of compensating fluctuations in oxygen availability. Besides tactic responses and physiological changes, many Gram positives including B. subtilis are able to employ sporulation in order to cope with conditions of very low energy yield. In B. subtilis, the sporulation initiating protein SpoOF needs to be activated by one of five kinases. One of these, KinA, carries three PAS domains and binds ATP (Piggot and Hilbert 2004). Therefore, it is probable that the complex network of sporulation control also involves a mechanism of energy sensing.

\section{Possible implication of energy taxis sensors in regulatory processes}

Little is known about the additional roles of MCP-like taxis sensors beside altering bacterial tactic behaviour. Since energy generation is one of the most important parameters of bacterial survival, it is not farfetched to speculate that sensing energetic conditions may result in more than only a single response. Besides directly, rapidly and actively seeking conditions of better energy generation by taxis, bacteria may, in parallel, adapt their cellular physiology to environmental conditions. An implication of specific MCPlike proteins which are not connected to taxis in gene regulation has already been suspected in several bacteria (Kirby 2009); prominent examples are found amongst species which use more than one set of che-like genes: Myxococcus xanthus uses MCPs to control spore formation (Kirby and Zusman 2003); likewise, M. xanthus (Berleman et al. 2008) also uses another distinct set of MCPs to control predataxis, which may indeed be one mode of energy taxis; MCPs act in initiating developmental processes such as flagellar biosynthesis or cyst formation in Rhodospirillum centenum (Berleman and Bauer 2005a, b) or they help to induce Cholera toxin in V. cholera (Lee et al. 2001). Only one published study currently supports the hypothesis that a dedicated energy taxis sensor can also be involved in gene regulation: the $E$. coli taxis sensor Aer affected transcription of genes involved in energy metabolism (Pruss et al. 2003). More precisely, in an Aer mutant, the genes $d m s A B C$ (DMSO reductase), $f d n G H I$ (formate dehydrogenase), frdABCD (fumarate reductase), glp $A B$ (glycerol 3-phosphate dehydrogenase), nrfABCDE (nitrite 
reductase) and the edd and eda genes important in anaerobic respiration were down-modulated (Pruss et al. 2003). The mechanism by which Aer would regulate these genes is still unresolved. The authors discuss either a direct influence on gene expression or an involvement of two component systems such as ArcAB or NarQP. The core chemotaxis proteins (CheA, CheY), which are the only proteins so far known to interact with MCP-like taxis sensors, appeared not to be involved in the observed gene regulation (Pruss et al. 2003). Interestingly, Aer-mediated responses are not subject to negative feedback adaptation by methylation (Bibikov et al. 2004). Thus, one could further hypothesize that the expression of genes encoding enzymes of the anaerobic respiration could be somehow induced by sustained Aer activation. However, as long as the molecular mechanisms of both gene regulation and redox sensing by Aer are not resolved, such a dual function of Aer in taxis and gene regulation remains speculative. Even in the absence of solid evidence, the fact that several other species besides $E$. coli use only one set of chemotaxis genes and possess only a small number of dedicated regulators (e.g. H. pylori and related bacteria; (Niehus et al. 2004; Beier and Frank 2000)) makes the idea all the more attractive that in those species, regulatory functions of taxis sensors may exist. Embedding sensors feeding the chemotaxis apparatus in gene regulation networks to achieve a better energy yield on the long run is a quite plausible hypothesis that should be tested further.

\section{Conclusion and open questions}

According to current knowledge, energy taxis seems to be a very important strategy for the survival of different freeliving or host-associated and pathogenic bacteria. In addition to genetic and regulatory diversification within a natural population, different strategies have evolved for facing the worst-case scenario of decreasing metabolic activity: One way is to "adapt" to unfavourable conditions, for example by changing their cellular physiology by gene regulation, to switch from aerobic to anaerobic respiration. A second strategy in "adapting" is "to wait until things get better", for example by sporulation. A more active and most rapid way to counteract a decrease in metabolic activity is to "search energy" on their own. Using energy taxis and a directed flagellar or non-flagellar motility, motile bacteria are able to navigate to their preferred niche. This activity ensures sustained survival, which in many cases, may just be around the next bend. Since bacterial energy taxis has only been characterized recently as a quite widespread mechanism, numerous questions as to its mechanisms of function and role remain to be investigated:
- How diverse is energy taxis within the bacterial world, what are its respective ecophysiological roles and which various kinds of bacterial motility behaviour can be summarized as energy taxis?

- What are the molecular mechanisms for energy taxiswhat exactly is sensed in each case?

- Which protein-protein interactions of bacterial energy taxis sensors contribute to their localization or function? How do MCP energy taxis sensors interact and cooperate with canonical MCPs and the chemotaxis core proteins?

- Do some intracellular energy taxis sensors interact with enzymes of the electron transport chain or with other metabolic enzymes directly (e.g. with enzymes that might be working as "trigger enzymes" or "moonlighting enzymes" (Commichau and Stulke 2008)

- Where are soluble MCP energy taxis sensors located within the cell and can their localization be dynamic?

- Do some bacterial energy taxis sensors influence gene expression and, if they do, what are the underlying molecular mechanisms?

Remains the interesting and provocative question how far microbial energy sensing and also taxis may be compared or evolutionarily linked to "hunger" sensing mechanisms in eukaryotes. Mechanisms of energy sensing related to taxis have been demonstrated in diverse eukaryotes. In plants, phototropins, also members of the PAS/LOV protein family, are involved in the relocation of plant chloroplasts in response to light (Alexandre et al. 2009). The vertebrate dual PAS protein HIF (hypoxia inducible factor 1) is sensing reactive oxygen species (ROS) produced by mitochondria and regulates genes important for coping with hypoxia (e.g. VEGF, EPO) (Taylor 2008). Also one master regulator of mitochondrial biogenesis, PGC- $1 \alpha$, is regulated by the NAD-dependent protein SIRT1 and the AMP:ATP ratio measuring protein AMPK (Feige and Auwerx 2007; Canto and Auwerx 2009). It is unknown how these events translate into oxygen- or energy-seeking motility in multicellular organisms or vertebrates. In addition to a proposed role of these proteins in actively seeking better conditions, they appear to regulate organelle (mitochondria, chloroplast) biogenesis and function, dependent on the energy and redox state of the cell. If one consequently follows the endosymbiont concept, the motility of organelles inside a permanent host cell or the transfer of a motility signal from an organelle to a multicellular superorganism could be regarded as an equivalent to energy taxis. Since energy-seeking behaviour is very important for all living organisms, energy taxis could be regarded as a global strategy and its overarching principles in all phyla of life should be further investigated. 
Acknowledgments We thank Sebastian Suerbaum and Dirk Hofreuter for helpful comments on the manuscript. We apologize to all colleagues whose excellent work on this fascinating topic we could not cite due to space restraints. Erko Stackebrandt and four anonymous reviewers are gratefully acknowledged for very helpful and expert suggestions. This work was supported by the network ERAnet PathoGenomics "HELDIVNET" funded by the German Ministry for Research and Education and by grant Jo 344/3-1 from the German research foundation.

Open Access This article is distributed under the terms of the Creative Commons Attribution Noncommercial License which permits any noncommercial use, distribution, and reproduction in any medium, provided the original author(s) and source are credited.

\section{References}

Adler J (1969) Chemoreceptors in bacteria. Science 166:1588-1597 Alam M, Lebert M, Oesterhelt D, Hazelbauer GL (1989) Methylaccepting taxis proteins in Halobacterium halobium. EMBO J 8:631-639

Alexandre G, Greer SE, Zhulin IB (2000) Energy taxis is the dominant behavior in Azospirillum brasilense. $\mathrm{J}$ Bacteriol 182:6042-6048

Alexandre G, Greer-Phillips S, Zhulin IB (2004) Ecological role of energy taxis in microorganisms. FEMS Microbiol Rev 28:113126

Alexandre MT, van Grondelle R, Hellingwerf KJ, Kennis JT (2009) Conformational heterogeneity and propagation of structural changes in the LOV2/Jalpha domain from Avena sativa phototropin 1 as recorded by temperature-dependent FTIR spectroscopy. Biophys J 97:238-247

Amin DN, Taylor BL, Johnson MS (2006) Topology and boundaries of the aerotaxis receptor Aer in the membrane of Escherichia coli. J Bacteriol 188:894-901

Armitage JP, Hellingwerf KJ (2003) Light-induced behavioral responses ('phototaxis') in prokaryotes. Photosynth Res 76:145-155

Baraquet C, Theraulaz L, Iobbi-Nivol C, Mejean V, Jourlin-Castelli C (2009) Unexpected chemoreceptors mediate energy taxis towards electron acceptors in Shewanella oneidensis. Mol Microbiol 73:278-290

Beier D, Frank R (2000) Molecular characterization of two-component systems of Helicobacter pylori. J Bacteriol 182:2068-2076

Berleman JE, Bauer CE (2005a) A che-like signal transduction cascade involved in controlling flagella biosynthesis in Rhodospirillum centenum. Mol Microbiol 55:1390-1402

Berleman JE, Bauer CE (2005b) Involvement of a Che-like signal transduction cascade in regulating cyst cell development in Rhodospirillum centenum. Mol Microbiol 56:1457-1466

Berleman JE, Scott J, Chumley T, Kirby JR (2008) Predataxis behavior in Myxococcus xanthus. Proc Natl Acad Sci USA 105:17127-17132

Bespalov VA, Zhulin IB, Taylor BL (1996) Behavioral responses of Escherichia coli to changes in redox potential. Proc Natl Acad Sci USA 93:10084-10089

Bibikov SI, Barnes LA, Gitin Y, Parkinson JS (2000) Domain organization and flavin adenine dinucleotide-binding determinants in the aerotaxis signal transducer Aer of Escherichia coli. Proc Natl Acad Sci USA 97:5830-5835

Bibikov SI, Miller AC, Gosink KK, Parkinson JS (2004) Methylationindependent aerotaxis mediated by the Escherichia coli Aer protein. J Bacteriol 186:3730-3737
Boin MA, Hase CC (2007) Characterization of Vibrio cholerae aerotaxis. FEMS Microbiol Lett 276:193-201

Bren A, Eisenbach M (2000) How signals are heard during bacterial chemotaxis: protein-protein interactions in sensory signal propagation. J Bacteriol 182:6865-6873

Brooun A, Bell J, Freitas T, Larsen RW, Alam M (1998) An archaeal aerotaxis transducer combines subunit I core structures of eukaryotic cytochrome c oxidase and eubacterial methyl-accepting chemotaxis proteins. J Bacteriol 180:1642-1646

Buron-Barral MC, Gosink KK, Parkinson JS (2006) Loss- and gainof-function mutations in the F1-HAMP region of the Escherichia coli aerotaxis transducer Aer. J Bacteriol 188:3477-3486

Canto C, Auwerx J (2009) PGC-1alpha, SIRT1 and AMPK, an energy sensing network that controls energy expenditure. Curr Opin Lipidol 20:98-105

Carlson CA, Ingraham JL (1983) Comparison of denitrification by Pseudomonas stutzeri, Pseudomonas aeruginosa, and Paracoccus denitrificans. Appl Environ Microbiol 45:1247-1253

Commichau FM, Stulke J (2008) Trigger enzymes: bifunctional proteins active in metabolism and in controlling gene expression. Mol Microbiol 67:692-702

Croxen MA, Sisson G, Melano R, Hoffman PS (2006) The Helicobacter pylori chemotaxis receptor TlpB (HP0103) is required for $\mathrm{pH}$ taxis and for colonization of the gastric mucosa. J Bacteriol 188:2656-2665

Cruz RH, Hoffmann T, Marino M, Nedjari H, Presecan-Siedel E, Dreesen O, Glaser P, Jahn D (2000) Fermentative metabolism of Bacillus subtilis: physiology and regulation of gene expression. $\mathrm{J}$ Bacteriol 182:3072-3080

Dzinic SH, Luercio M, Ram JL (2008) Bacterial chemotaxis differences in Escherichia coli isolated from different hosts. Can J Microbiol 54:1043-1052

Earl AM, Losick R, Kolter R (2008) Ecology and genomics of Bacillus subtilis. Trends Microbiol 16:269-275

Eaton KA, Suerbaum S, Josenhans C, Krakowka S (1996) Colonization of gnotobiotic piglets by Helicobacter pylori deficient in two flagellin genes. Infect Immun 64:2445-2448

Edwards JC, Johnson MS, Taylor BL (2006) Differentiation between electron transport sensing and proton motive force sensing by the Aer and Tsr receptors for aerotaxis. Mol Microbiol 62:823837

El Mashtoly SF, Gu Y, Yoshimura H, Yoshioka S, Aono S, Kitagawa T (2008) Protein conformation changes of HemAT-Bs upon ligand binding probed by ultraviolet resonance Raman spectroscopy. J Biol Chem 283:6942-6949

Elliott KT, DiRita VJ (2008) Characterization of CetA and CetB, a bipartite energy taxis system in Campylobacter jejuni. Mol Microbiol 69:1091-1103

Elliott KT, Zhulin IB, Stuckey JA, DiRita VJ (2009) Conserved residues in the HAMP domain define a new family of proposed bipartite energy taxis receptors. J Bacteriol 191:375-387

Feige JN, Auwerx J (2007) Transcriptional coregulators in the control of energy homeostasis. Trends Cell Biol 17:292-301

Fu R, Wall JD, Voordouw G (1994) DcrA, a c-type heme-containing methyl-accepting protein from Desulfovibrio vulgaris Hildenborough, senses the oxygen concentration or redox potential of the environment. J Bacteriol 176:344-350

Galimand M, Gamper M, Zimmermann A, Haas D (1991) Positive FNR-like control of anaerobic arginine degradation and nitrate respiration in Pseudomonas aeruginosa. J Bacteriol 173:15981606

Gauden DE, Armitage JP (1995) Electron transport-dependent taxis in Rhodobacter sphaeroides. J Bacteriol 177:5853-5859

Genin S, Boucher C (2004) Lessons learned from the genome analysis of Ralstonia solanacearum. Annu Rev Phytopathol 42:107-134 
Greer-Phillips SE, Alexandre G, Taylor BL, Zhulin IB (2003) Aer and Tsr guide Escherichia coli in spatial gradients of oxidizable substrates. Microbiology 149:2661-2667

Greer-Phillips SE, Stephens BB, Alexandre G (2004) An energy taxis transducer promotes root colonization by Azospirillum brasilense. J Bacteriol 186:6595-6604

Hazelbauer GL, Falke JJ, Parkinson JS (2008) Bacterial chemoreceptors: high-performance signaling in networked arrays. Trends Biochem Sci 33:9-19

Hendrixson DR, Akerley BJ, DiRita VJ (2001) Transposon mutagenesis of Campylobacter jejuni identifies a bipartite energy taxis system required for motility. Mol Microbiol 40:214-224

Hoff WD, van der Horst MA, Nudel CB, Hellingwerf KJ (2009) Prokaryotic phototaxis. Methods Mol Biol 571:25-49

Hong CS, Kuroda A, Ikeda T, Takiguchi N, Ohtake H, Kato J (2004a) The aerotaxis transducer gene aer, but not aer-2, is transcriptionally regulated by the anaerobic regulator ANR in Pseudomonas aeruginosa. J Biosci Bioeng 97:184-190

Hong CS, Shitashiro M, Kuroda A, Ikeda T, Takiguchi N, Ohtake H, Kato J (2004b) Chemotaxis proteins and transducers for aerotaxis in Pseudomonas aeruginosa. FEMS Microbiol Lett 231:247-252

Horne SM, Mattson KR, Pruss BM (2009) An Escherichia coli aer mutant exhibits a reduced ability to colonize the streptomycintreated mouse large intestine. Antonie Van Leeuwenhoek 95:149-158

Hou S, Larsen RW, Boudko D, Riley CW, Karatan E, Zimmer M, Ordal GW, Alam M (2000) Myoglobin-like aerotaxis transducers in Archaea and Bacteria. Nature 403:540-544

Johnson MS, Zhulin IB, Gapuzan ME, Taylor BL (1997) Oxygendependent growth of the obligate anaerobe Desulfovibrio vulgaris Hildenborough. J Bacteriol 179:5598-5601

Kato J, Kim HE, Takiguchi N, Kuroda A, Ohtake H (2008) Pseudomonas aeruginosa as a model microorganism for investigation of chemotactic behaviors in ecosystem. J Biosci Bioeng 106:1-7

Kavermann H, Burns BP, Angermuller K, Odenbreit S, Fischer W, Melchers K, Haas R (2003) Identification and characterization of Helicobacter pylori genes essential for gastric colonization. J Exp Med 197:813-822

Khan S, Spudich JL, McCray JA, Trentham DR (1995) Chemotactic signal integration in bacteria. Proc Natl Acad Sci USA 92:97579761

Kirby JR (2009) Chemotaxis-like regulatory systems: unique roles in diverse bacteria. Annu Rev Microbiol 63:45-59

Kirby JR, Zusman DR (2003) Chemosensory regulation of developmental gene expression in Myxococcus xanthus. Proc Natl Acad Sci USA 100:2008-2013

Lancaster CR, Simon J (2002) Succinate: quinone oxidoreductases from epsilon-proteobacteria. Biochim Biophys Acta 1553:84101

Lee L, Mizuno T, Imae Y (1988) Thermosensing properties of Escherichia coli tsr mutants defective in serine chemoreception. J Bacteriol 170:4769-4774

Lee SH, Butler SM, Camilli A (2001) Selection for in vivo regulators of bacterial virulence. Proc Natl Acad Sci USA 98:6889-6894

Lee DY, Ramos A, Macomber L, Shapleigh JP (2002) Taxis response of various denitrifying bacteria to nitrate and nitrite. Appl Environ Microbiol 68:2140-2147

Letunic I, Doerks T, Bork P (2009) SMART 6: recent updates and new developments. Nucleic Acids Res 37:D229-D232

Losi A, Gartner W (2008) Bacterial bilin- and flavin-binding photoreceptors. Photochem Photobiol Sci 7:1168-1178

Marchant J, Wren B, Ketley J (2002) Exploiting genome sequence: predictions for mechanisms of Campylobacter chemotaxis. Trends Microbiol 10:155-159
McGee DJ, Langford ML, Watson EL, Carter JE, Chen YT, Ottemann KM (2005) Colonization and inflammation deficiencies in Mongolian gerbils infected by Helicobacter pylori chemotaxis mutants. Infect Immun 73:1820-1827

Miller LD, Russell MH, Alexandre G (2009) Diversity in bacterial chemotactic responses and niche adaptation. Adv Appl Microbiol 66:53-75

Nakano MM, Zuber P (1998) Anaerobic growth of a "strict aerobe" (Bacillus subtilis). Annu Rev Microbiol 52:165-190

Ng WO, Grossman AR, Bhaya D (2003) Multiple light inputs control phototaxis in Synechocystis sp. strain PCC6803. J Bacteriol 185:1599-1607

Nichols NN, Harwood CS (2000) An aerotaxis transducer gene from Pseudomonas putida. FEMS Microbiol Lett 182:177-183

Niehus E, Gressmann H, Ye F, Schlapbach R, Dehio M, Dehio C, Stack A, Meyer TF, Suerbaum S, Josenhans C (2004) Genomewide analysis of transcriptional hierarchy and feedback regulation in the flagellar system of Helicobacter pylori. Mol Microbiol 52:947-961

Ordal GW, Villani DP, Rosendahl MS (1979) Chemotaxis towards sugars by Bacillus subtilis. J Gen Microbiol 115:167-172

Piggot PJ, Hilbert DW (2004) Sporulation of Bacillus subtilis. Curr Opin Microbiol 7:579-586

Pruss BM, Campbell JW, Van Dyk TK, Zhu C, Kogan Y, Matsumura P (2003) FlhD/FlhC is a regulator of anaerobic respiration and the Entner-Doudoroff pathway through induction of the methylaccepting chemotaxis protein Aer. J Bacteriol 185:534-543

Rebbapragada A, Johnson MS, Harding GP, Zuccarelli AJ, Fletcher HM, Zhulin IB, Taylor BL (1997) The Aer protein and the serine chemoreceptor Tsr independently sense intracellular energy levels and transduce oxygen, redox, and energy signals for Escherichia coli behavior. Proc Natl Acad Sci USA 94:1054110546

Schreiber S, Konradt M, Groll C, Scheid P, Hanauer G, Werling HO, Josenhans C, Suerbaum S (2004) The spatial orientation of Helicobacter pylori in the gastric mucus. Proc Natl Acad Sci USA 101:5024-5029

Schreiber S, Bucker R, Groll C, Azevedo-Vethacke M, Garten D, Scheid P, Friedrich S, Gatermann S, Josenhans C, Suerbaum S (2005) Rapid loss of motility of Helicobacter pylori in the gastric lumen in vivo. Infect Immun 73:1584-1589

Schweinitzer T, Mizote T, Ishikawa N, Dudnik A, Inatsu S, Schreiber S, Suerbaum S, Aizawa S, Josenhans C (2008) Functional characterization and mutagenesis of the proposed behavioral sensor TlpD of Helicobacter pylori. J Bacteriol 190:3244-3255

Sellars MJ, Hall SJ, Kelly DJ (2002) Growth of Campylobacter jejuni supported by respiration of fumarate, nitrate, nitrite, trimethylamine-N-oxide, or dimethyl sulfoxide requires oxygen. J Bacteriol 184:4187-4196

Spudich EN, Sundberg SA, Manor D, Spudich JL (1986) Properties of a second sensory receptor protein in Halobacterium halobium phototaxis. Proteins 1:239-246

St Maurice M, Cremades N, Croxen MA, Sisson G, Sancho J, Hoffman PS (2007) Flavodoxin:quinone reductase (FqrB): a redox partner of pyruvate:ferredoxin oxidoreductase that reversibly couples pyruvate oxidation to NADPH production in Helicobacter pylori and Campylobacter jejuni. J Bacteriol 189:4764-4773

Stingl K, Uhlemann EM, Schmid R, Altendorf K, Bakker EP (2002) Energetics of Helicobacter pylori and its implications for the mechanism of urease-dependent acid tolerance at $\mathrm{pH} 1$. J Bacteriol 184:3053-3060

Suerbaum S, Josenhans C, Sterzenbach T, Drescher B, Brandt P, Bell M, Droege M, Fartmann B, Fischer H-P, Ge Z, Hörster A, Holland R, Klein K, König J, Macko L, Mendz GL, Nyakatura G, Schauer DB, Shen Z, Weber J, Frosch M, Fox JG (2003) The 
complete genome sequence of the carcinogenic bacterium Helicobacter hepaticus. Proc Natl Acad Sci USA 100:79017906

Sun Y, Gustavson RL, Ali N, Weber KA, Westphal LL, Coates JD (2009) Behavioral response of dissimilatory perchlorate-reducing bacteria to different electron acceptors. Appl Microbiol Biotechnol 84:955-963

Szurmant H, Ordal GW (2004) Diversity in chemotaxis mechanisms among the bacteria and archaea. Microbiol Mol Biol Rev 68:301-319

Takata T, Fujimoto S, Amako K (1992) Isolation of nonchemotactic mutants of Campylobacter jejuni and their colonization of the mouse intestinal tract. Infect Immun 60:3596-3600

Taylor BL (2007) Aer on the inside looking out: paradigm for a PASHAMP role in sensing oxygen, redox and energy. Mol Microbiol 65:1415-1424

Taylor CT (2008) Mitochondria and cellular oxygen sensing in the HIF pathway. Biochem J 409:19-26

Taylor BL, Zhulin IB (1999) PAS domains: internal sensors of oxygen, redox potential, and light. Microbiol Mol Biol Rev 63:479-506

Taylor BL, Miller JB, Warrick HM, Koshland DE Jr (1979) Electron acceptor taxis and blue light effect on bacterial chemotaxis. J Bacteriol 140:567-573

Taylor BL, Zhulin IB, Johnson MS (1999) Aerotaxis and other energy-sensing behavior in bacteria. Annu Rev Microbiol 53:103-128

Taylor BL, Rebbapragada A, Johnson MS (2001) The FAD-PAS domain as a sensor for behavioral responses in Escherichia coli. Antioxid Redox Signal 3:867-879

Tran QH, Unden G (1998) Changes in the proton potential and the cellular energetics of Escherichia coli during growth by aerobic and anaerobic respiration or by fermentation. Eur $\mathrm{J}$ Biochem 251:538-543

Ulrich LE, Zhulin IB (2010) The MiST2 database: a comprehensive genomics resource on microbial signal transduction. Nucleic Acids Res 38:D401-D407

Umemura T, Matsumoto Y, Ohnishi K, Homma M, Kawagishi I (2002) Sensing of cytoplasmic $\mathrm{pH}$ by bacterial chemoreceptors involves the linker region that connects the membrane-spanning and the signal-modulating helices. J Biol Chem 277:1593-1598

Vander WC, Pierard A, Kley-Raymann M, Haas D (1984) Pseudomonas aeruginosa mutants affected in anaerobic growth on arginine: evidence for a four-gene cluster encoding the arginine deiminase pathway. J Bacteriol 160:928-934

Vegge CS, Brondsted L, Li YP, Bang DD, Ingmer H (2009) Energy taxis drives Campylobacter jejuni toward the most favorable conditions for growth. Appl Environ Microbiol 75:5308-5314
Wadhams GH, Armitage JP (2004) Making sense of it all: bacterial chemotaxis. Nat Rev Mol Cell Biol 5:1024-1037

Watts KJ, Johnson MS, Taylor BL (2008) Structure-function relationships in the HAMP and proximal signaling domains of the aerotaxis receptor Aer. J Bacteriol 190:2118-2127

Weingarten RA, Grimes JL, Olson JW (2008) Role of Campylobacter jejuni respiratory oxidases and reductases in host colonization. Appl Environ Microbiol 74:1367-1375

Williams SM, Chen YT, Andermann TM, Carter JE, McGee DJ, Ottemann KM (2007) Helicobacter pylori chemotaxis modulates inflammation and bacterium-gastric epithelium interactions in infected mice. Infect Immun 75:3747-3757

Wong LS, Johnson MS, Zhulin IB, Taylor BL (1995) Role of methylation in aerotaxis in Bacillus subtilis. J Bacteriol 177:3985-3991

Xie Z, Ulrich LE, Zhulin IB, Alexandre G (2010) PAS domain containing chemoreceptor couples dynamic changes in metabolism with chemotaxis. Proc Natl Acad Sci USA 107:2235-2240

Yao J, Allen C (2006) Chemotaxis is required for virulence and competitive fitness of the bacterial wilt pathogen Ralstonia solanacearum. J Bacteriol 188:3697-3708

Yao J, Allen C (2007) The plant pathogen Ralstonia solanacearum needs aerotaxis for normal biofilm formation and interactions with its tomato host. J Bacteriol 189:6415-6424

Yao VJ, Spudich JL (1992) Primary structure of an archaebacterial transducer, a methyl-accepting protein associated with sensory rhodopsin I. Proc Natl Acad Sci USA 89:11915-11919

Yao R, Burr DH, Guerry P (1997) CheY-mediated modulation of Campylobacter jejuni virulence. Mol Microbiol 23:1021-1031

Ye RW, Tao W, Bedzyk L, Young T, Chen M, Li L (2000) Global gene expression profiles of Bacillus subtilis grown under anaerobic conditions. J Bacteriol 182:4458-4465

Yoon SS, Hennigan RF, Hilliard GM, Ochsner UA, Parvatiyar K, Kamani MC, Allen HL, DeKievit TR, Gardner PR, Schwab U, Rowe JJ, Iglewski BH, McDermott TR, Mason RP, Wozniak DJ, Hancock RE, Parsek MR, Noah TL, Boucher RC, Hassett DJ (2002) Pseudomonas aeruginosa anaerobic respiration in biofilms: relationships to cystic fibrosis pathogenesis. Dev Cell 3:593-603

Zhang W, Brooun A, McCandless J, Banda P, Alam M (1996) Signal transduction in the archaeon Halobacterium salinarium is processed through three subfamilies of 13 soluble and membrane-bound transducer proteins. Proc Natl Acad Sci USA 93:4649-4654

Zhulin IB, Bespalov VA, Johnson MS, Taylor BL (1996) Oxygen taxis and proton motive force in Azospirillum brasilense. $\mathrm{J}$ Bacteriol 178:5199-5204 